\title{
Lectura(s): hacia una revisión del concepto'
}

\author{
Reading(s): Towards a Concept Review \\ MELISA GISELA MAINA \\ VANINA PAPALINI \\ Universidad Nacional de Córdoba \\ Argentina \\ melisa.maina@gmail.com \\ v.a.papalini@gmail.com
}

(Recibido: $\mathrm{I}_{4}-\mathrm{O} 4-2 \mathrm{O} 2 \mathrm{O}$; aceptado: $22-\mathrm{IO}-2 \mathrm{O} 2 \mathrm{O}$ )

Resumen. La práctica de la lectura no ha tenido las mismas connotaciones a lo largo de la historia. Evidenciando cambios importantes en su conceptualizando en las últimas décadas. En este artículo nos preguntamos qué es leery cómo se relaciona la lectura literaria con la comprensión. Para dar cuenta de ello, primero revisaremos algunas definiciones teóricas presentes en el campo. Esto nos permitirá el armado de un mapa de las diferentes concepciones sobre esta práctica. El objetivo es proponer una definición establecida en base a seis de sus dimensiones: estética; lúdica; cognitiva; sociocultural; subjetiva y corporal-afectiva.

Palabras clave: lectura; experiencia estética; afectividad; juego; comprensión.
Abstract. The practice of reading has not had the same connotations throughout history. This study shows important changes in its conceptualization in the last decades. This article reflects on what reading is and how literary reading is related to comprehension. To account for that, some theoretical definitions present in the field are reviewed.This will allow us to put together a map of the different conceptions of this practice. The objective is to propose a definition based on six dimensions: aesthetics; playful; cognitive; sociocultural; subjective, and corporal-affective.

Keywords: reading; experience; aesthetics; affectivity; game; comprehension.

\footnotetext{
I Para citar este artículo: Maina, Melisa Gisela y Papalini, Vanina (2O2I). Lectura(s): hacia una revisión del concepto. Álabe 23 · [www.revistaalabe.com]

DOI: IO.I5645/Alabe2O2I.23.5
} 


\section{¿Qué es leer?}

No vemos las cosas como son, vemos las cosas como somos.

Anaïs Nin

¿Qué es leer? Esta pregunta puede adquirir respuestas muy variadas y diversas. Leer muchas veces es representado como “devorar". La "deglución” literaria es tanto metafórica como literal, como lo relata David Livingstone, un médico, explorador y misionero británico que realizó diversas expediciones en África en el siglo diecinueve. Entre sus anécdotas de viaje, cuenta un encuentro con un grupo de pobladores a quienes les muestra un libro que ha sobrevivido a las dificultades del viaje. La lectura resulta una práctica incomprensible para la tribu, al menos en la forma en que la entendemos en el mundo occidental, y esto desencadena un episodio confuso: los nativos roban el libro y lo devoran para intentar emular la satisfacción que le causaba a Livingstone (Huey, I9O8:2). ${ }^{2}$ De este episodio no deberían extraerse conclusiones rápidas; también en las sociedades europeas existe el "bibliovorismo", tal como relata Whitehead (2002). La lectura no es la única práctica posible en relación al libro; este objeto puede usarse, fetichizarse o simbolizarse de diferentes maneras.

Aunque parezca fruto de un consenso colectivo, las concepciones sobre la lectura se fundan en criterios disímiles, en cuyo trasfondo operan presupuestos y expectativas diversos. Parece de sentido común asumir su valor; sin embargo, la "naturalidad" de tal creencia es fruto de una larga y contradictoria historia en la cual la lectura, en determinados períodos, fue concebida como nociva para la salud (Littau, 2008:23). Una pequeña nota histórica puede ayudarnos a recordar que las "verdades evidentes", no lo son en absoluto: a fines del siglo XIX, se pensaba que la "fiebre lectora" era una enfermedad provocada por la lectura excesiva. Entre sus síntomas, se citan los siguientes: constipación, vientre flácido, alteraciones de la vista y el cerebro, afecciones nerviosas y enfermedades mentales.

Durante el siglo XIX, los efectos de estas patologías desencadenadas por la lectura se hicieron tan alarmantes que fueron tratadas por la medicina. Para los antiguos médicos, el lector se comportaba como un adicto que necesitaba desesperadamente ese estímulo y no podía dejar de consumir un libro tras otro. Esto podría provocar diversas afecciones, según el médico Simon A. Tissot: "perjudicaría los ojos, el cerebro, los nervios" (Abreu, 2002: I2). La adicción a la lectura lleva a leer excesivamente y de manera obsesiva, empujando a los lectores de una novela a la siguiente, como el Don Quijote retratado por Cervantes, arrastrado a la locura por su afición desmesurada a los libros de caballería. Vale decir que la lectura literaria fue considerada peligrosa. Según

\footnotetext{
${ }^{2}$ To the early peoples, reading was one of the most mysterious of the arts, both in its performance and in its origins. We recall how, even in modern times, Livingstone excited the wonder and awe of an African tribe as he daily perused a book that had survived the vicissitudes of travel. So incomprehensible to these savages ( sic ), was his performance with the book, that they finally stole it and ate it, as the best way they knew of "reading" it, of getting the white man's satisfaction from it (Huey, I9O8:2).
} 
Karin Littau: "La recepción por parte del público de novelas valiosas escritas por figuras literarias (...) indicaba hasta qué punto la ficción podía ser mortífera (...)” (2008:Io6).

$\mathrm{Al}$ examinar estas referencias, comprendemos que la lectura literaria no parece trabajar sólo en el plano cognitivo sino que compromete energética y emocionalmente la integralidad del cuerpo. Entonces, ¿dónde comienza y termina la práctica de la lectura literaria o de obras de ficción? La lectura es una práctica que comienza antes y continúa más allá del acto de leer, construyendo subjetividades. Existen distintas líneas de estudio y muchas de ellas establecen una distancia entre lectura comprensiva y lectura literaria. Entendiendo que la lectura es una práctica múltiple y rica, el objetivo de este artículo es proponer una definición abarcadora que integre sus distintas dimensiones. Para ello, recorreremos diferentes perspectivas y propondremos un enfoque que considera su implicación a nivel estético, lúdico, cognitivo, sociocultural, subjetivo y corporalafectivo.

\section{Hacia una definición de lectura multidimensional}

La Real Academia Española sostiene que la lectura es la: "I. Acción de leer. 2. Obra o cosa leída. 3. Interpretación del sentido de un texto” (RAE, 2O2O). Ahora bien, entre la acción de la lectura y la interpretación de un sentido, hay algunas otras definiciones posibles y es necesario hacer un poco de historia.

La lectura es un hecho antiguo. Se cree que el alfabeto fue inventado por un pueblo semítico alrededor del I5Oo (a.C) en algún lugar de la Mesopotamia (Ong, 2OII: 9I). Los problemas de la lectura que nos interesa analizar son mucho más recientes y se relacionan con la alfabetización de masas, que data del siglo XIX. Hasta entonces, la lectura era una actividad reservada para algunas clases sociales, que dependía en gran medida de los servicios religiosos (Darnton, I993). En las primeras teorías de la lectura, la comprensión era concebida como un simple reflejo del pensamiento (Whipple, I9I7).

La alfabetización masiva acarrea nuevas preocupaciones sobre qué y quiénes leen. En la década de I950, los científicos relacionan los procesos cognitivos, en auge por esas fechas, con la lectura comprensiva (Fries y Pikes, I949). La lectura comienza a ser entendida como un conjunto de habilidades (Dubois, I996). Algunos de sus referentes de estas teorías fueron el educador norteamericano William Gray (I937) y los psicólogos John Carroll (r976), Eleanor Gibson y Harry Levin (1975). Esta concepción surge asociada a la alfabetización obligatoria y entiende a la lectura en un proceso jerarquizado de habilidades que abarcan desde lo más simple a lo más complejo; desde la identificación de las letras hasta la decodificación de la frase. Se pensaba que, si se enseñaban los primeros niveles de manera sólida, se accedería a la lectura completa del texto. Cabe destacar que Gray sostenía que la lectura era un acto total y no la suma de sus partes pero, en las estrategias de enseñanza de la época, este último aspecto fue pocas veces tomado en consideración. 
Cuando la lectura es concebida como un conjunto de habilidades que deben ser alcanzadas unas tras otras, su enseñanza implica una serie de actividades mecánicas en una secuencia rígida. El paradigma del modelo mecanicista, ${ }^{3}$ que impacta fuertemente en la forma de comprender y explicar el mundo, también se aplica a la lectura. En términos de Dubois: "Casi todos los métodos de enseñanza de la lectura vigentes hasta hoy, se desarrollaron en mayor o menor medida sobre la base de esta concepción” (I996: 24). Este enfoque considera que la enseñanza de la lectura, tanto en los niños como en los adultos, está constituida por niveles, en el siguiente orden: I) el reconocimiento de palabras; 2) la comprensión; 3) la reacción emocional; y 4) la asimilación o evaluación.

Esta perspectiva pionera muestra una simplicidad en la que no quedaba contemplada la complejidad de la lectura. Otras líneas teóricas intentan reponer los aspectos vacantes. Subyace un remanente de esta idea en la enseñanza de la lectura en los primeros grados escolares, cuando se espera que, desmenuzando en pequeñas unidades (sílabas, letras), se llegue finalmente a alcanzar el texto completo.

Afinales de los años 6o, la lectura comienza apensarsecomo un proceso interactivo (Dubois, r996). A diferencia de la concepción de la lectura como conjunto de habilidades, en esta línea el lector tiene un papel activo, se presupone que busca conocimientos almacenados en su memoria y los proyecta en el sentido del texto. La lectura aparece como un objeto de estudio recurrente de la psicolingüística. Kenneth Goodman (i976) propone un modelo que contempla la lectura como una interacción entre el lector y el texto, como proceso psicolingüístico donde interactúan el pensamiento y el lenguaje. Dentro de esta misma perspectiva, Frank Smith (I980) destaca el papel de la información no visual que posee el lector, que completa la información del texto. Es esa combinación la que configura el sentido de la lectura: la construcción del significado se lleva a cabo a través del uso que el lector hace de la información grafónica, sintáctica y semántica que el texto ofrece.

A partir de $197 \mathrm{O}$, el eje comienza a centrarse en el lector y cómo comprende un texto (Littau, 2008:3I). En Alemania, en la Universidad de Constanza, se forma un grupo de teóricos representados por Hans Georg Gadamer quien insiste en el proceso de interpretación del lector. Sus alumnos Hans Robert Jauss y Wolfgang Iser formarán el núcleo duro de esta línea de investigación.

Wolfgang Iser, en su obra clave, El acto de leer (I987), estudia las posibilidades y efectos del texto literario en su interacción histórica con el sujeto receptor. Aquí introduce una categoría de enorme importancia para nuestra crítica: el concepto de "lector implícito" (Iser, I987: 7O). Iser lo concibe como una creación en la mente del autor en el proceso de escribir, que luego puede o no coincidir con los lectores empíricos, o sea las personas reales que leen una novela o un poema. El texto es concebido como una

\footnotetext{
${ }^{3}$ El modelo mecanicista se inspira en el pensamiento científico de Newton, que se propaga en todas las áreas del conocimiento. El universo se consideraba una parte completa que podía ser descompuesta en partes más pequeñas. Así, se considera que la lectura puede ser descompuesta en partes más pequeñas para ser enseñadas.
} 
materialidad que deja espacios en blanco -en términos de sentido- a ser llenados por el lector. Es decir, el sentido es recuperado por un lector que va uniendo y desarrollando esos virtuales espacios en blanco. Por su parte, en Estados Unidos se desarrolla el Readerresponse criticism con teóricos como Gerald Prince, Stanley E. Fish (I980) y Jonathan Culler.

En este mismo período, Louise Rosenblatt propone una relación doble y recíproca entre el lector y el texto, entendiendo la lectura como proceso transaccional. Si bien esta teoría no es considerada relevante en su momento, fue revisitada posteriormente, alcanzando el crédito que ameritaba (Dubois, I996). Esta autora reflexiona en torno a la lectura entendiéndola como un proceso dinámico entre el texto y el lector, como una interacción que permite construir un significado, pero este depende de las condiciones sociales y culturales del lector.

A su vez, Pugh (1978), Lunzer y Gardner (1979) describen varios estilos de lectura. Enfocándose en la didáctica de las lenguas extranjeras, desarrollan el concepto de "lectura intensiva" que consiste en leer con atención, buscando todos los detalles, para poder responder preguntas sobre el texto. Diferencian esta modalidad de la "lectura extensiva" que tiene como objetivo la lectura rápida de textos largos, sin centrarse en los detalles.

Entre 1980 y 1990 , el lector es concebido como un sujeto socialmente situado en claves sociohistóricas. Esta es la concepción de la sociología de la lectura, que había comenzado a desarrollarse en el período de entreguerras (Poulain, 20II). A partir de la década de I980, en pleno auge de las políticas culturales, esta corriente analiza la potencial involución de los procesos lectores. Dentro de esta línea, los enfoques cualitativos en la sociología de la lectura, como los de Lahire (2004), Bahloul (I998), Peroni (I988) y Petit (2006), muestran que la facultad fundamental de un lector no se refiere solo a qué o cuánto lee, sino a la manera en que capitaliza la lectura en su vida social, afectiva, política o laboral.

En términos de políticas de lectura, su promoción y su obligatoriedad son preceptos relativamente nuevos. Esta práctica, que fuera prohibida o se reservara para una élite, se convierte en una práctica universal incentivada por los Estados. Sin embargo, no constituye una obligación a cumplir bajo pena de sanción ni puede forzarse: un o una estudiante puede enrolarse forzosamente en un sistema educativo, pero no se le puede "imponer" la competencia lectora. Allí es justamente donde se revela la peculiaridad de esta práctica, que no se adquiere como un simple hábito repetitivo y automático. Hay "algo más" implicado que es subjetivo, voluntario y singular. La lectura reclama, interpela al lector, y se frustra si este no se involucra.

Este anclaje subjetivo, que aparece esbozado por la Escuela de Constanza, adquiere características distintas en algunos autores y autoras contemporáneos. Dice Michèle Petit: “(...) el lector no consume pasivamente el texto; se lo apropia, lo interpreta, modifica su sentido, desliza su fantasía, su deseo y sus angustias entre las líneas y los entremezcla con los del autor. Y es allí, en toda esa actividad fantasmática, en ese trabajo 
psíquico, donde el lector se construye" (2008:28). Para esta autora, la lectura construye subjetividad y permite una reelaboración propia de cada sujeto en términos de la historia leída. La dimensión subjetiva también es considerada por Jorge Larrosa (2003), quien relaciona la lectura con la posibilidad de construcción, a través de la palabra, de una identidad anclada en el mundo circundante.

En una posición post-estructuralista, Roland Barthes (I987) recupera la figura del lector que había quedado rezagada detrás de la figura de autor. Trastocando la perspectiva, Barthes indica que la lectura literaria se convierte en un resquicio, en un punto de fuga, donde la estructura se modifica.

El placer, ${ }^{4}$ para él, se convierte en el lugar intersticial en donde son posibles otras maneras de leer. Sostiene: "No es la 'persona' del otro lo que necesito, es el espacio: la posibilidad de una dialéctica del deseo, de una imprevisión del goce: que las cartas no estén echadas sino que haya juego todavía" (r993: 28). Otros intelectuales se han referido también a la lectura literaria en un sentido parecido. Michel De Certeau (I979) propone, de manera metafórica, que leer es una cacería furtiva que remite a una nueva forma de nomadismo en unas sociedades altamente normadas y sedentarias como lo son las occidentales

Noé Jitrik, por su parte, establece que se sabe poco de la lectura a pesar de ser una práctica cotidiana. Dice: “(...) leer es transformar lo que se lee, que deviene, de este modo, un objeto refractado, interpretado, modificado (...)" (I982:II). Jitrik introduce la idea, no de la transformación del sujeto a través de la lectura, sino la transformación de la lectura a través del sujeto. Dos escritoras recuperan esa manera de pensar: Graciela Montes afirma que la lectura es un poder "(...) que tiene el que juega mientras está jugando" (2005:32), mientras que María Teresa Andruetto (2018) sostiene que se trata de un bastión de resistencia.

Estas interpretaciones de la lectura literaria ponen el acento en algunos de los aspectos implicados, sin articularlos completamente. Es por ello que consideramos necesario un concepto integral que reúna estas características, que resultan un poco elusivas en términos del análisis en razón de su labilidad, cuando remiten a dimensiones subjetivas, o su multidimensionalidad. Se trata de distintas perspectivas que toman a Jauss y los tipos de recepción estética como antecedente.

Si comprendemos a la lectura literaria como una práctica sociocultural que involucra dimensiones tanto objetivas como subjetivas, no parece tan fácil someterla a un escrutinio cuantitativo. ¿Qué ignoramos cuando medimos la lectura como si fuera un acto unitario, bien delimitado? Proponemos entender la lectura literaria en distintas dimensiones desagregadas. Cada una de ellas identifica el carácter dominante en una experiencia múltiple. Creemos que esta reconceptualización puede servir de base para un desarrollo ulterior de estrategias de lectura comprensiva que resulten más ricas y eficaces.

${ }^{4}$ Placer y goce son nociones centrales en la obra de Roland Barthes. Ver por ejemplo: Elplacer del texto (i974) y El susurro del lenguaje: Más allá de la palabra y de la escritura (I987). 
Partimos de las siguientes premisas. Consideramos la lectura:

a) como una experiencia subjetiva. Creemos que la lectura literaria es uno de los pocos espacios de resistencia en un mundo de subjetividad controlada. ¿Cuál es el significado de la experiencia estética y cómo se relaciona con la subjetividad? En otra publicación, propusimos: "La experiencia es, a nivel del sujeto singular, una de las formas de la "alteridad radical" capaz de implosionar la subjetividad; es aquello no normado, la emergencia disruptora que ocasiona la crisis. Es a la psiquis, lo que al acontecimiento al mundo social" (Papalini, 20I6: 29).

La lectura puede ser pensada como una experiencia, lo que sucede al sujeto en un aquí y ahora en un momento determinado. Jorge Larrosa sostiene: "La experiencia supone, ya he dicho, un acontecimiento exterior a mí. Pero el lugar de la experiencia soy yo" (2006: 89). Así, la experiencia se convierte en un eje vertebral para pensar esta investigación porque permite pensar en las otras aristas: experiencia estética, juego y ficción, comprensión y subjetividad.

b) como acción material asociada a un soporte específico: el libro. La lectura nos hace revisar qué leemos, qué entendemos por libro o texto. La escritora Laura Devetach (2008) utiliza un concepto más amplio de texto, donde incorpora los textos escritos y conjunto de producciones de la cultura. Es necesario establecer que sabemos que existen múltiples definiciones de lectura, sin embargo creemos que el tema no está agotado y que reclama una conceptualización que permita condensar los aspectos que hemos ido señalando a lo largo de estos dos primeros capítulos.

c) como proceso cognitivo en sí mismo, y como vía de acceso al conocimiento. La lectura es la forma de acceso a la información y podemos decir que se complementa con la capacidad de análisis para traducir el discurso escrito, la capacidad de síntesis para retomar las ideas principales y generar paráfrasis, y capacidad de lectura crítica para expresar sus propios puntos de vista. Por lo tanto, es un proceso que implica un acceso al modo de conocer el mundo.

d) como práctica sociocultural, materialmente vinculada a los contextos; ellos actúan como matrices de interpretación y claves de construcción de significaciones.

Conviene aclarar que distinguimos las significaciones del sentido.

Estas formas de entender la lectura literaria no son contradictorias entre sí. Más bien, revelan que se trata de una práctica multidimensional. En ese sentido, en vez de optar por una definición que excluya a las restantes, proponemos entenderla en sus distintas dimensiones. Así, de esta revisión de teorías y nociones, surge un concepto único, que concibe la lectura como una práctica sociocultural a un tiempo subjetiva y objetiva, vinculada a un libro o texto, que constituye un proceso cognitivo en sí mismo y por el cual se accede a un universo de saberes letrados. Proponemos desagregar este concepto en seis dimensiones: 
I-Dimensión estética

2-Dimensión lúdica

3-Dimensión comprensiva

4-Dimensión de la experiencia subjetiva

5-Dimensión sociocultural

6- Dimensión corporal-afectiva

Estos seis aspectos, amalgamados, son la base del concepto de lectura que intentamos construir.

\section{I-Dimensión estética de la lectura}

Esta dimensión se refiere a la lectura literaria como una relación entre el lector y el arte. La posibilidad de disfrute de un objeto artístico difícilmente pueda enseñarse, en términos de instrucción teórica. ¿Cómo explicamos esa experiencia? ¿Qué tiene de particular? Hans Jauss, uno de los fundadores de la Escuela de Constanza, esbozó algunas respuestas.

En debate con las concepciones fundamentalistas en torno a la obra de arte, Jauss colocó al sujeto en el centro: la obra de arte es importante por la experiencia que le produce al receptor. De este modo, la recepción de una obra de arte es significativa para estudiar, para comprender. A su vez, considera que el arte funda una apropiación cognoscitiva del mundo, es decir, aporta un conocimiento valioso. La primera tesis de Jauss afirma: "La actitud de goce, que desencadena y posibilita el arte, es la experiencia estética primordial; no puede ser excluida, sino que ha de convertirse de nuevo en objeto de reflexión teórica (1972: 3I).”

Esto quiere decir que, a través del arte, a través de la lectura literaria, el ser humano se reconoce y se abre a otros universos. La experiencia estética configura una forma de acercarse al mundo y la realidad. Podemos reconocer en nosotros mismos esa potencialidad: ¿cuántas veces una lectura ha modificado nuestra percepción de mundo?

El arte es el lugar de la experiencia significativa donde los seres humanos aprenden acerca de sí mismos y del mundo, además de estremecerse y gozar. Ese encuentro con la obra literaria también se produce una ganancia cognoscitiva. Las obras de arte son signos cuyo sentido es mostrar cómo muestran lo que muestran (Jauss, 1972: 20). Y allí es donde reside la posibilidad de una experiencia estética, un tipo de experiencia que sucede en presente y cuya ganancia cognoscitiva se produce en el contacto con la obra. Ese contacto puede generar dicha o alegría, pero también angustia.

Esto nos lleva a pensar en el lugar asignado a la lectura socialmente: en una sociedad que suele establecer una oposición entre trabajar y disfrutar, se debe justificar continuamente la experiencia estética. Como consecuencia, la lectura literaria se ha visto tironeada entre el imperativo de la productividad y el disfrute estético. Esta escisión 
no siempre se hace conscientemente: aunque se proclama la importancia de la lectura, incluso de la lectura literaria o por puro placer, no se rompe fácilmente con el paradigma de la utilidad, a tal punto que en la escuela, la lectura literaria aparece como "ocasión" para enseñar gramática o redacción, por ejemplo.

Creemos que su interés y valor van en otra dirección. La fruición estética transporta imaginativamente hacia una "experiencia de segundo grado": las obras de arte no nos sacan del mundo de nuestras experiencias ni nos liberan de él, sino que nos dan la libertad de comportarnos de diferente manera. Jauss ha expresado esta posición al decir que la experiencia estética no es una liberación de (los vínculos con la praxis, con el mundo de la vida) sino una liberación para (un comportamiento modificado en y con respecto a esa praxis). La dinámica entre la obra y el lector es mucho más profunda que sólo una decodificación de los signos. Por lo tanto, entendemos que la ficción habilita un lugar para poder poner estos conceptos a disposición de una comprensión cabal de los textos.

\section{2-Dimensión lúdica de la lectura}

La experiencia de la lectura, en su contrato transicional, permite pensar en el lector como un jugador. Esta dimensión es productiva para analizar las múltiples estrategias que despliega el lector cuando lee, sustentadas en un entramado social. Johan Huizinga (20I5) sostiene que el juego es más viejo que la cultura y excede al hombre, ya que los animales también juegan. De allí el nombre que propone Huizinga para designarnos: Homo Ludens, un término que señala la importancia del juego en la definición de humanidad, siendo este una de las base de la cultura.

La lectura-juego abre la experiencia del disfrute a partir de la búsqueda y la expectativa; la inmersión en la lectura supone un compromiso similar a meterse en un juego. Jean Marie Schaeffer (2002) sostiene que la experiencia ficcional se realiza en un fingimiento lúdico compartido, que se relaciona con asumir roles (dentro del texto y en el juego) y aceptar las reglas (dentro del texto y en el juego). Para esto, debe existir un consenso social, una base sobre la cual poder articular las reglas. Esa base es lo que permite lograr que la lectura sea una práctica compartida con otros. La ficción es un "vector de inmersión", como propone Schaeffer (2002: 228), y se convierte en la puerta de entrada y salida en las historias propuestas. Por "vector de inmersión", Schaeffer comprende una actividad cognitiva que se realiza ante la historia de ficción, que no sólo está presente en la lectura sino también en el teatro o los medios audiovisuales.

La ficción lúdica establece una interfaz subjetiva que permite compartir un mundo, relacionándonos directamente con los otros. Esta dimensión involucra tres elementos: incertidumbre, intencionalidad y tiempo. Graciela Montes (20I8) ofrece un ejemplo que muestra el paralelismo entre la lectura y el juego. Para ella, ambas prácticas comparten la incertidumbre como característica. Tanto el lector como el jugador entran 
en un terreno desconocido que no será posible conocer totalmente hasta el final.

Por su lado, Ana Malajovich (2009) sostiene que lo esencial del juego, tal vez sobre lo que menos se ha reflexionado, es la intencionalidad: sólo hay juego cuando los sujetos deciden convertirse en jugadores, creando la situación de juego. Sin esta decisión libre y voluntaria, el juego no existe. Este supone siempre riesgo, desafío, desconocimiento del resultado y de los avatares de su desarrollo; de allí la idea de incertidumbre. En sus palabras: "La intención de los jugadores es jugar, y esta es la única certeza del juego" (Malajovich, 2009:I4). Cuando leemos, así como cuando jugamos, no sabemos qué sucederá, aunque haya ciertas reglas preestablecidas. La intención es una de las premisa fundantes del juego, comenzamos el juego o leemos cuando lo decidimos.

Esto nos lleva a un tercer elemento, aquel que Michel Picard sostiene cuando dice: "La lectura del niño, si lee, se inserta en uso del tiempo como un juego entre otros (I986:IO)."5 La cita se refiere al tiempo, un tiempo propio (el tiempo de la realidad del juego) que plantea una cesura con una rutina existencial suspendiendo -al igual que la ficción- las reglas del mundo circundante. La libertad, la procesualidad y la construcción colectiva -o al menos interpersonal- de reglas, son componentes centrales de este mundo "otro". El lector puede considerarse un "jugador" que construye sentidos a través de los objetos o palabras que se van presentando. De este modo, el lector puede ordenar creativamente los elementos que tiene a disposición.

La lectura literaria, en su dimensión lúdica, permite entender que el lector se mueve en el texto como lo hace el jugador en el tablero o en el espacio de juego. La incertidumbre, la intencionalidad y el tiempo propio son componentes de una dimensión que permite pensar en el juego como un eje central de la cultura. Esto implica entender lógicas propias de la lectura de ficción y recuperar su lugar central en las prácticas educativas, relacionada tanto con la comprensión de mundo como con el trabajo sobre la subjetividad. Se establece así un doble anclaje: en la dimensión social y en la experiencia individual, lo que conduce a entender y conocer a partir del disfrute estético. Lejos de reducir lo lúdico a lo recreativo, lo comprendemos aquí como parte esencial de la cultura.

\section{3-Dimensión cognitiva}

Aquí entendemos que la lectura literaria es un proceso cognitivo que involucra varias aristas, de las cuales una es la comprensión. Es una práctica que puede plantear de manera distinta los procesos de enseñanza-aprendizaje y puede resultar una forma (placentera) de conocer. Ampliamos la idea: la lectura es la forma de acceso a la información; se despliega junto con la capacidad de análisis para traducir el discurso escrito, la capacidad de síntesis para retomar las ideas principales y generar paráfrasis, y capacidad de lectura crítica para expresar los propios puntos de vista. Por ello, es un

\footnotetext{
5 La lecture de l' enfant, s'il lit, s 'insère dans son emploi du temps comme un jeu parmi d'autres jeux.
} 
camino de acceso al mundo tanto como un modo de conocerlo. En ese enclave, la ficción funciona a modo de bisagra entre el mundo y los lectores. En otras palabras, podemos conocer de otras emociones, otras culturas porque la lectura literaria nos interpela desde lo que no vimos, ni oímos pero que a través del relato ficcional podemos reconstruir en un conocimiento esbozado en palabras.

Ahora bien, ese camino muchas veces queda escindido en lecturas diferentes o con otros objetivos. Las lecturas literarias que tienen como fin "cultivarse" son aparentemente distintas de aquellas que se utilizan para fines didácticos. Las lecturas literarias parecen no tener un objetivo instrumental o ulterior. No se lee "para algo", sino por el placer de hacerlo; leer como juego; leer como esparcimiento o para pasar (más que para matar) el tiempo. Los textos didácticos, en cambio, son más bien expositivos; ofrecen información y proponen trabajo, mientras que la ficción pertenece al ocio. Placer y educación no parecen entenderse bien. El modelo mecanicista de la lectura ha impregnado fuertemente las aulas y esto repercute en los modos de enseñanza. ${ }^{6}$ Este enfoque considera que la enseñanza de la lectura, tanto en los niños como en los adultos, está constituida por niveles, en el siguiente orden: I) el reconocimiento de palabras; 2) la comprensión; 3) la reacción emocional; y 4) la asimilación o evaluación. Dice María Eugenia Dubois: "Casi todos los métodos de enseñanza de la lectura vigentes hasta hoy, se desarrollaron en mayor o menor medida sobre la base de esta concepción” (I996: 24). El paradigma del modelo mecanicista, que impacto fuertemente en la forma de comprender y explicar el mundo, también se aplica a la lectura. Dubois continúa diciendo: "El impacto de las nuevas concepciones de la lectura en la práctica pedagógica- a diferencia de lo que sucedido con el modelo mecanicista- ha sido hasta ahora muy débil” (I996: 25). Esto implica que corren dos ríos paralelos; el más caudaloso propicia la utilización la lectura literaria fraccionándola; el río más angosto considera la experiencia estética como eje central de la lectura en las instituciones educativas. Sin embargo, en ese leer (lectura literaria) "para no hacer nada" está involucrado el concepto de comprensión ya que, para poder disfrutar de esa actividad, es requerido entender el sentido del texto. Dice María Nikolajeva:

En resumen, la relación entre el mundo real y su representación ficticia constituye una brecha cognitiva sustancial que exige una serie de habilidades cognitivas y metacognitivas. La suposición de mi argumento es que los lectores novatos no poseen estas habilidades o aún no las han desarrollado completamente, y esa ficción puede potencialmente estimular este desarrollo hacia la experiencia lectora. ${ }^{7}(2 \mathrm{OI} 4: 4)$

\footnotetext{
${ }^{6}$ El modelo mecanicista refiere a la predominancia del pensamiento científico de Newton en todas las áreas del conocimiento. El universo se consideraba una parte completa que podía ser descompuesta en partes más pequeñas. Así se consideraba que la lectura podía ser descompuesta en partes más pequeñas para ser enseñadas.

7 In summary, the relationship between the actual world and its fictional representation constitutes a substantial cognitive gap that demands a number of cognitive and metacognitive skills. The assumption of my argument is that novice readers do not possess these skills or have not yet fully developed them, and that fiction can potentially stimulate this development toward reading expertise.
} 
¿Cuáles son las implicancias cognitivas en la lectura literaria? Como veíamos en la dimensión anterior, existe un espacio desde donde la lectura literaria permite emprender un proceso cognitivo planteado de una forma muy particular: los lectores se relacionan con la ficción desde el espacio lúdico. ¿Es posible aprender a partir de la ficción? ¿En qué términos? ¿Qué se aprende?

María Nikolajeva sostiene que los lectores establecen pactos ficcionales y pueden aprender a partir de la lectura realizando un intercambio entre lo que saben y lo que el libro les muestra como novedoso o desconocido. Uno de los propósitos de la ficción es transmitir experiencia "refractada a través de una conciencia individual" (Nikolajeva 20I4:40). Para complejizar la idea que propone la autora, entendemos que no sólo usamos nuestra experiencia de la vida real para entender la narrativa, sino que el mundo de las historias ayuda a iluminar y explicar el mundo real, de modo que el "compromiso cognitivo" de la ficción es un proceso bidireccional: de vida a texto y de texto a vida" (Nikolajeva 20I4:25).

En esa doble dimensión de relación entre el texto y el lector se produce una ganancia cognoscitiva en términos estéticos y también una transformación de la subjetividad. Las relaciones entre conocer, comprender y leer están dadas por estas dimensiones que planteamos y que construyen un vínculo entre prácticas que parecen escindidas: la lectura literaria y la lectura que permite un aprendizaje.

\section{4-Dimensión sociocultural}

Como ya expusimos, Wolfgang Iser estudia las posibilidades y efectos del texto literario en su interacción histórica con el sujeto receptor. Ahora bien, la pregunta es cómo comprender a un lector empírico, a una persona de carne y hueso, un sujeto que selecciona un texto literario, entre muchos, y lo interpreta de acuerdo con una intención proléptica indisociable de cualquier actividad humana. A su vez esa práctica está inserta en una trama sociocultural que tiene sus lógicas de sentido. El lector de textos de ficción acepta el marco propuesto por el narrador mediante el acto de una suspensión voluntaria de la incredulidad, admite el juego de la ficción y se sumerge en la lectura desde esos parámetros. Participa y construye un sentido en la relación entre el texto y el contexto que no es genérico sino específico, vinculado a su universo de vida, es decir, "apropiado”. El entramado en donde se produce el sentido, en la lectura de ficción, refracta el plexo de significaciones socioculturales.

Como dice Clifford Geertz: “(...) el hombre es un animal inserto en tramas de significación que él mismo ha tejido”: estas significaciones son públicas, exteriores, anteriores e independientes de sí mismo. Aclara: "considero que la cultura es esa urdimbre" (2003:20) y más adelante, explica: "La cultura, ese documento activo, es pues pública, lo mismo que un guiño burlesco o una correría para apoderarse de ovejas. Aunque contiene ideas, la cultura no existe en la cabeza de alguien; aunque no es física, no es una 
entidad oculta" (2003:24). E insiste: "La cultura es pública porque la significación lo es. Uno no puede hacer una guiñada (o fingir burlescamente una guiñada) sin conocer lo que ella significa o sin saber cómo contraer físicamente el párpado (...)” (2003:26).

Aldecir quelalecturaes una práctica sociocultural,lainscribimos enla materialidad del mundo. La comprensión, que implica la construcción de significaciones, no es realizada por un agente individual autónomo sino que implica insertarse en esas tramas culturales, que son públicas y objetivas. Pero la lectura es una práctica "reversible": si es objetiva en tanto trama de significaciones, deviene subjetiva cuando construye sentidos, que siempre son "para” alguien. El sentido es una apropiación, un pliegue subjetivo, construido con (pero no sólo) significaciones.

\section{5-Dimensión de la experiencia subjetiva}

Es cierto que algunas actividades humanas pueden ser explicadas, diseñadas y planificadas por otros; pero la lectura no pertenece a este tipo. La lectura literaria se arraiga en las profundidades del sujeto y por esta razón es válido interrogarse sobre la construcción de subjetividad de los niños en sus primeras relaciones con los libros. Puede hipotetizarse que la dimensión subjetiva es poco aprehensible para el investigador, difícil de desentrañar, pero elabora una serie de cuestiones en relación a la concreción de sueños y realidades que vale la pena explorar. Michèle Petit específica: "Leer, o escuchar leer en voz alta, sirve ante todo para crear esos otros espacios esenciales para la expansión de uno mismo -y el olvido de uno mismo-, sobre todo cuando no se cuenta con ningún territorio personal” (2OII:3). Es una apertura hacia la creación de espacios individuales. ${ }^{8}$

La noción de "subjetividad", como la tratamos aquí, se refiere a una dimensión del sujeto que, participando de su existencia -es decir, la subjetividad es socialmente producida-, exhibe una dinámica propia. Este pliegue reflexivo implica la capacidad del locutor de plantearse como "sujeto". Siguiendo a Emile Benveniste (I968), la subjetividad se define, no por el sentimiento que cada quien experimenta de ser él mismo (sentimiento que, en la medida en que es posible considerarlo, no es sino un reflejo), sino como la unidad psíquica que trasciende la totalidad de las experiencias vividas, que reúne y que asegura la permanencia de la conciencia. Así, para Benveniste, el fundamento de la subjetividad está en el ejercicio de la lengua, que se convierte en el mejor "testimonio objetivo" de la identidad del sujeto que da él mismo sobre sí mismo.

El lenguaje está organizado de tal forma que permite a cada locutor apropiarse la lengua entera designándose como yo. La instalación de la "subjetividad" en el lenguaje

\footnotetext{
${ }^{8}$ La noción de subjetividad de Michèle Petit es mucho más individual que el modo en el que aquí nos la planteamos. Benveniste, por su parte, la vuelve una función del lenguaje. En nuestro caso, seguimos una perspectiva deleuziana que considera a la subjetividad como una invaginación del "afuera", del mundo existente que nos produce como sujetos. La variante que propone Gilles Deleuze en relación a este suelo que comparte con Michel Foucault, es que ese intersticio pueden generarse dinámicas que habiliten la torsión de los procesos de subjetivación.
} 
crea, en el lenguaje y - creemos- fuera de él también, la categoría de la persona. ¿Cómo se relaciona esto con la lectura? La literatura potencia esa experiencia transformadora para construir otra mirada sobre el mundo. Al asumir la palabra e incorporarla en la subjetividad, comienza un proceso de revisión sobre nosotros mismos. Jorge Larrosa sostiene: "La experiencia supone, ya he dicho, un acontecimiento exterior a mí. Pero el lugar de la experiencia soy yo" (2006: 89).

A su vez, la palabra es comunicante; podemos tratar de entender al otro a partir de su discurso. Eso no es un dato menor en una investigación social en el ámbito educativo. Si bien no podemos comprender totalmente la dimensión subjetiva de una persona, podemos aproximarnos a partir de su palabra.

Para Petit (2006, 2008), la lectura es espacio de construcción de la subjetividad, porque se constituye en un lugar a habitar, donde se pueden desarrollar una construcción sobre uno mismo. En plena infancia, la literatura posibilita un espacio de construcción propia, de revisión del mundo que habitamos. Así se convierte en una pieza fundamental en los años de la niñez, porque no se trata sólo de la comprensión del lenguaje sino de la posibilidad de construir un mundo propio.

Luiz Percival Leme Britto confirma: "Y, tal vez, uno de los valores más expresivos de nuestro tiempo, la subjetividad, inherente a cada uno y la consecuente afirmación de la individualidad, es una de las cuestiones más difíciles de lidiar y de comprender" (2OIO:9). Leme Britto construye la experiencia de la lectura como un lugar de reflexividad. Así, en una sociedad que se distingue por lo fugaz, la posibilidad de la experiencia íntima, sin tiempo, es por sí sola una forma de resistencia. La lectura permite potenciar las posibilidades de emancipación. Lo interesante es la manera en la que lo hace.

No toda lectura literaria desencadena los mismos procesos, y por ello es una práctica que si bien puede ser indicada y repetida en su dimensión objetiva, es decir, como práctica, como acción, su apropiación no puede ser "legislada" ni prescrita. La dinámica que desencadena la "máquina lectora"9 es completamente contingente e incierta. Esta indeterminación abre el espacio propio, se establece un diálogo subjetivo que ayuda a la transformación y recreación identitaria. Y en esa intimidad, la lectura puede configurar una experiencia.

Nos distanciamos así de una lectura instrumental, como la escolar, para enfatizar en la movilización de líneas que emergen en una interrelación entre la lectura y la vida real. La experiencia permite una ruptura con los órdenes establecidos del mundo conocido. La lectura puede convertirse en una experiencia; puede significar un momento crucial, puede dejar huella; puede ayudar a construir la palabra propia.

\footnotetext{
9 Llamamos así, retomando la definición de máquina de Gilles Deleuze y Felix Guattari (1977) a la interacción que se produce entre la lectura y el lector, causa y efecto de múltiples líneas anudadas provisoriamente que se replican o se insubordinan a partir de allí.
} 


\section{6-Dimensión corporal-afectiva}

El proceso de lectura, para Petit, comienza con situaciones de intersubjetividad gratificantes. "Allí se abren puertas hacia lugares distintos para construir una posición de sujeto" (Petit, 2008:27). La lectura, en cuanto operación cognitiva, permite compartir un mundo y relacionarnos directamente con los otros. En esa interfaz intersubjetiva es donde construimos un lugar que permite la inmersión lúdica, el compartir con los otros.

Martin Jay (2009) considera la dimensión corporal dentro de su cronología de la evolución del concepto de experiencia; para él la experiencia estética viene a colocar el cuerpo en el centro. La experiencia adquiere materialidad en el cuerpo. En general, nos inclinamos a pensar que la lectura es comprensión y ocupa exclusivamente nuestra cabeza. Sin embargo, leer implica el cuerpo, levantar la mirada, estremecerse, sonreír, cerrar los ojos. Karin Littau dice al respecto: "La historia literaria está colmada de referencias a la lectura en cuanto experiencia que afecta profundamente al lector. Ya sea que produzca lágrimas de pena, accesos de carcajadas o nos ponga los cabellos de punta, todos esos síntomas comprometen al cuerpo." (2008:I9) Es decir, la lectura se engarza en el cuerpo. Esta dimensión se traduce muchas veces en una necesidad de tocar lo que se está leyendo, o con el rechazo a la página ${ }^{\mathrm{IO}}$.

La dimensión afectiva implica una revisión entre los lazos que se establecen entre los sujetos y los objetos. Existe una dimensión afectiva relacionada con los primeros libros que leemos. No necesariamente recordamos las historias, sino algunos aspectos del libro como objeto. Este lector adulto recapitula sobre su experiencia lectora haciendo hincapié en qué recuerda de su infancia. Dice Carlos Silva, evocando su trayectoria de lectura: “... mentiría si dijera que leía sus contenidos. Lo que realmente me atraía era la imagen de su portada, y más aún la imagen de la portada del próximo número, que aparecía en miniatura en la sección editorial” (en Papalini, 20I6:56).

También en investigaciones con niños se establecen vínculos emocionales muy fuertes con los autores de los libros que más les gustan. Por ejemplo: "Me encanta Lauren Child” "г (toma el libro y lo besa) (Arizpe y Styles, 20I2: 85). Ese vínculo establecido con el libro está en relación con la dimensión de la experiencia estética mencionada anteriormente. La lectura es una práctica que permite encontrar una relación con el objeto, es decir el libro, que trasciende el gesto del abrazo.

Lo que pervive en la elaboración propia de cada lectura no es sólo el argumento, muchas veces ni siquiera lo guardamos en nuestra memoria, sino que la experiencia del contacto con el papel, la cubierta o los aromas. Otra lectora empírica adulta, reflexionando sobre sus lecturas de infancia, dice: "El papel era grueso, y las letras muy agradables, las ilustraciones eran pocas pero grandes, salpicadas por todo el libro. Dejaban siempre con

\footnotetext{
Io También el abrazo como parte del agradecimiento de la lectura de un cuento.

${ }^{\text {II }}$ Lauren Child es una autora de libros infantiles.
} 
ganas de más, sólo insinuaban” (Gil Juárez en Papalini, 20I6:I3I). Podemos observar que un vínculo con los libros puede generar una dimensión afectiva que no necesariamente es reproducible para todos por igual. Al menos, eso manifiesta esta lectora: "Me fascinaron, aunque a nadie más a mi alrededor parecían suscitarle ningún interés” (Gil Juárez en Papalini, 20I6:Io6).

Louise Rosenblatt establece la noción de "experiencias vicarias" (2002), que se refiere a las sensaciones y emociones que se viven a través de las experiencias de otras personas. Por ejemplo, el sentir dolor cuando a un deportista le dan una patada, o la alegría cuando dos enamorados se casan en una serie de televisión. Es una forma muy poderosa de comunicación: no apela a la racionalidad, sino a la emoción, vivida en primera persona a través de una transposición narrativa. Esta forma de afectividad, una empatía que facilita la comprensión de la lectura, otorga las posibilidades de conocer otros mundos y otras vidas. Tal concepto permite entender que la literatura es un modo de anclar la palabra propia en sentimientos compartidos, suscitando una intercomprensión con el mundo. Rosenblatt sostiene: “(...) la comprensión es un proceso personal mucho más complejo de lo que muchos están dispuestos a admitir” (2002:I33).

Todo lo que concierne a la práctica de lectura tiene mucho que ver con la relación que se establecen con los demás, con las miradas cómplices, las risas, como un acto afectivo y recíproco de comprensión y de inserción ante el mundo.

\section{A modo de conclusión}

Como síntesis, sostenemos que la lectura literaria es un proceso cognitivo complejo mediado por la experiencia estética y anclado en la interfaz que produce en su vínculo lúdico con la ficción. Aun cuando la experiencia estética no pueda ser simbolizada totalmente, afecta -enriquece- nuestra forma de entender el mundo. Por lo tanto, es un proceso cognitivo en sí mismo, y es una vía de conocimiento.

Es al mismo tiempo un juego con reglas; una práctica sociocultural compartida que permite y supone la relación con los otros. En la interfaz intersubjetiva construimos un lugar que permite la inmersión en la lectura. Así se abre la posibilidad de desarrollo de la subjetividad. Esto quiere decir que la lectura literaria, en tanto experiencia estética, produce modificaciones en la subjetividad a partir de las emociones. Ofrece un espacio abierto, en un mundo de subjetividad controlada.

La lectura literaria puede ser pensada como una experiencia, lo que sucede al sujeto en un aquí y ahora en un momento determinado, que conjuga disfrute estético y conocimiento; juego y comprensión; subjetividad e interpretación. En ese sentido, leer literatura supone una construcción de mundo propia, un acercamiento al conocimiento que invita a repensar la relación ente una lectura literaria destinada al ocio y una lectura para informarse. La lectura literaria puede verse complejizada en las siguientes dimensiones: 
- Dimensión estética: La lectura es concebida como una experiencia particular frente a una obra de arte. De ese encuentro puede ocurrir una experiencia significativa donde los seres humanos aprenden acerca de sí mismos y del mundo, además de estremecerse y gozar. A su vez de ese encuentro, también se produce una ganancia cognoscitiva. Esa ganancia se puede observar en un tiempo no inmediato.

- Dimensión lúdica: indica que la lectura, en su constitución, contiene un componente relacionado con el juego que permite generar diferentes dinámicas en la práctica lectora. La ficción, e se convierte en el vector de inmersión (Schaeffer, 2002: 228), es decir, una actividad cognitiva que se realiza ante la historia de ficción. Ese vector actúa como interfaz, es decir como una relación particular que genera el lector con la lectura.

La dimensión lúdica de la lectura es una operación que establece variaciones -jugadas- dentro de un marco regulado. Como en un juego de equipo, la lectura permite compartir su mundo y relacionarnos directamente con los otros, pero también posibilita el juego singular, es decir, la defensa de un mundo propio único. Por ello, podemos decir que propone un doble anclaje, en la dimensión cultural y la experiencia individual.

- Dimensión cognitiva: Se refiere a la capitalización de la lectura literaria en términos de entendimiento individual del sentido de un texto. Es en ese proceso donde descubre un sentido y una forma de construir lo que está diciendo el texto. Es decir, el sentido es recuperado por un lector que va uniendo y desarrollando esos espacios en blanco.

- Dimensión sociocultural: Está en relación con la anterior e implica considerar que la comprensión de un texto o libro no es abstracta ni uniforme; estáasociada a matrices interpretativas socioculturales. La comprensión no está en relación unidireccional con las capacidades cognitivas del sujeto sino también con el nivel sociocultural. La comprensión se produce dentro de matrices culturales (Hoggart, 1957)..$^{\text {I2 }}$ No podemos intentar entender la comprensión para todos de la misma forma.

- Dimensión de la experiencia subjetiva: permite entender que la lectura de ficción habilita un espacio particular donde es posible encontrar una voz propia. La "subjetividad" que aquí tratamos es la capacidad del locutor de plantearse como "sujeto" (Benveniste, I968). La palabra es el vehículo de transmisión de la subjetividad, ya que podemos tratar de entender al otro a partir de su voz. Esto se vuelve un potencial lugar de emancipación porque la revisión subjetiva e interior es posible solo en y por el sujeto.

\footnotetext{
${ }^{12}$ En el libro Uses of Literacy. Aspects of Working-Class Life (1957), Hoggart recupera la alfabetización en las clases obreras, para evidenciar que los receptores obreros jugaban un papel activo, ya que tenían la capacidad de aceptar, negociar o rechazar el mensaje que recibían de parte de los medios masivos de comunicación. A su vez el entorno social, cultural, educativo y político influye en la forma de adquisición del mensaje.
} 
- Dimensión corporal-afectiva: El cuerpo es una superficie de afectación, un espacio en el que la lectura se inscribe. La lectura no es una práctica que se registra solo a nivel de los ojos sino que involucra todo el cuerpo. Tampoco es puramente mental sino que integra las emociones. Este proceso establece un vínculo no prescribible. Es decir, no estamos ante una forma de enseñar emociones a través de la ficción, sino que buscamos destacar de qué manera los lectores se relacionan con los libros a través de diferentes sentimientos que no siempre son de alegría, cariño o felicidad. Muchas veces se desencadenan otras emociones como la tristeza, el enojo, el rencor, la angustia o la nostalgia.

Queda al descubierto, así, la relación que la lectura literaria guarda con la emotividad. Al contrario de lo que reza el credo positivista, la emoción no perjudica, sino al contrario: facilita un aprendizaje. La división de la lectura entre lo útil y lo placentero conlleva la dificultad para relacionarlo cognitivo con lo afectivo, lo mental con el cuerpo. La lectura atraviesa al lector y construye un lugar propio y subjetivo que puede ser amplificación de lo social. Esta forma de concebir la lectura es un aporte que puede nutrir nuevas formas de enseñarla, de propiciarla, de acercarse a ella. 


\section{Bibliografía}

-Abreu, M. (2002). ¿Qué y por qué están leyendo los niños y jóvenes de hoy? México: CONACULTA.

-Andruetto, M.T. (20I8). Resistencia. Buenos Aires: Los nuevos cuadernos de ALIJA.

Arizpe, E. y Styles, M. (2OI2). Lectura de imágenes. Los niños interpretan textos visuales. México: Fondo de Cultura Económica.

- Bahloul, J. (1998). Lecturas precarias. Estudio sociológico sobrelos "pocoslectores". México: Fondo de Cultura Económica.

- Barthes, R. (1987). Sobre la lectura. El susurro del lenguaje. Más allá de la palabra y la escritura. Barcelona: Paidós.

- Barthes, R. (1993). Elplacer del texto. Madrid: Siglo XXI.

- Benveniste, E. (i968). De la subjetividad en el lenguaje. En E. Benveniste. Problemas de Lingüistica General. (pp. I79-I86). México: Siglo XXI.

- Carroll, J.B. (i976). The Nature of the Reading Process. En H. Singer y R. B Rudell, Theoretical Models of Processes of reading. Newark: IRA.

- Chartier, R. (i994). De la historia del libro a la historia de la lectura. En R. Chartier. Libros, lecturas y lectores en la Edad Moderna. Madrid: Alianza, I3-40.

- Chartier, A. M. (2005). Enseñar a leer y escribir. Una aproximación histórica. México: Fondo de Cultura Económica.

- Darnton, R. (1993). Historia de la lectura. Formas de hacer historia. Madrid: Alianza Universidad.

- De Certeau, M. (1979). La invención de lo cotidiano. México: Universidad Iberoamericana.

- Deleuze, G. y Guattari, F. (2004). Mil mesetas. Valencia: Pre-Textos.

- Devetach, L. (2008). La construcción del camino lector. Córdoba: Comunicarte.

- Dubois, M. E. (1996). El proceso de la lectura. De la teoría a la práctica. Buenos Aires: Aique didáctica.

- Fish, S. (1980). Is There a Text in This Class? The Authority of Interpretative Communities. Massachusetts: Harvard University Press 
- Fries, C. y Pike, K. L. (I949). Coexistent phonemic systems. Language 25, 25-50.

- Geertz, C. (2003). La interpretación de las culturas. Barcelona: Gedisa.

- Gibson, E.J. y Levin, H. (1975). The Psychology of reading. Cambridge: MIT Press.

- Goodman, K. (i976). Reading: A Psychoinguistic Guessing Game. En H. Singer y R. B. Rudell (Eds.) Theoretical Models and Processes of Reading. Newark: IRA.

- Gray, W. S. (1937). The nature and types of reading. Thirty-sixth yearbook of the national society for the study of education. Bloomington: Public School Publishing.

- Hoggart, R. (1957). Uses of Literacy. Aspects of Working-Class Life. London: Penguin Modern Classics.

- Huey, E. B. (1908). Psychology and pedagogy of reading, with a review of the history of reading and writing and of methods, texts, and hygiene in reading. New York: Macmillan.

- Huizinga, J. (20I5). Homo Ludens. Buenos Aires: El libro de bolsillo.

• Jauss, R. H. (1972). Pequeña apología de la experiencia estética. Barcelona: Paidós.

- Jay, M. (2009). Cantos de experiencia. Variaciones modernas sobre un tema universal. Buenos Aires: Editorial Paidós.

- Jitrik, N. (1982). La lectura como actividad. México: Premia editora de libros.

- Iser, W. (1987). El acto de leer: teoría del efecto estético. Madrid: Taurus.

- Lahire, B. (2004). Sociología de la lectura. Barcelona: Gedisa.

- Larrosa Bondía, J. (2003). La experiencia de la lectura. Estudios sobre literatura y formación. México: Fondo de Cultura Económica.

- Larrosa Bondía, J. (2006). Sobre la experiencia. Aloma: revista de psicologia, ciències de l'educació $i$ de l'esport Blanquerna, I9, 87-II2. Obtenido el I8 de septiembre de 2019 de: https://www.raco.cat/index.php/Aloma/article/view/ıo3367

- Leme Britto, L. (20I0). Inquietudes y desacuerdos: la lectura más allá de lo obvio. Bogotá: Asolectura.

- Littau, K. (2008). Teorías de la lectura: libros, cuerpo y bibliomanía. Buenos Aires: Manantial. 
- Lunzer, E. y Gardner, K. (I979). The efective use of reading. London: Heinemann Eucational books for the schools Council.

- Malajovich, A. (2009). Las concepciones infantiles acerca del juego. Cadernos de Educação, 34, 253-264.

- Montes, G. (2005). Las plumas del ogro. La importancia de lo raro en la lectura. Revista Imaginaria $\mathrm{N}^{\circ}{ }_{165}$. Obtenido el 3 de enero de 2020 de: http://www.imaginaria.com. ar/I6/5/las-plumas-del-ogro.htm

- Montes, G. (20I8). El bosque y el lobo. Construyendo sentidos en tiempos de industria cultural y globalización forzada. En G. Montes. Buscar indicios, construir sentido (pp.I3II62). Bogotá: Babel.

- Nikolajeva, M. (20I4). Reading for Learning: Cognitive approaches to children's literature. Amsterdam: John Benjamins Publishing Company.

- Ong, W. (2OII). Oralidad y escritura. Tecnologías de la palabra. México: Fondo de cultura económica.

- Papalini, V. (20i6). Forjar un cuarto propio. Villa María: Eduvim.

- Peroni, M. (1988). Historias de lectura. Trayectorias de vida y de lectura. México: Fondo de cultura económica.

- Petit, M. (2006). Lecturas: del espacio íntimo al espacio público. México: Fondo de Cultura Económica.

- Petit, M. (2008). El arte de la literatura en tiempos de crisis. Buenos Aires: Océano.

- Picard, M. (I986). La lecture comme jeu. París: Les éditions de Minuit.

- Pike, K. L. y Charles, C. F. (1949). Coexistent phonemic systems. Language 25, 25-50.

- Poulain, M. (20II). Una mirada a la sociología de la lectura. Perfiles educativos ${ }^{2} 2$ (33), pp. $195^{-204}$.

- Real Academia española (2020). Diccionario de la lengua española, $23 \cdot{ }^{\mathrm{a}} \mathrm{ed}$.

- Pugh, A. (1978). Silent reading: An introduction to its study and teaching. London: Heineman.

- Rosenblatt, L. (2002). La literatura como exploración. México: Fondo de Cultura Económica. 
- Schaeffer, J. M. (2002). ¿Por qué la ficción? Madrid: Lengua de Trapo.

- Smith, F. (1980). Reading. Cambridge: Cambridge University Press.

-Whipple, G. M. (I9I7). Editorials: The teaching of reading. Journal of Educational Psychology, 8(6), 378-379. http://dx.doi.org/ıo.Io37/hoo7o8I3

- Whitehead, G. (2002). Hungry for god. Cabinet 7. http://www.cabinetmagazine.org/ issues/ 7 /hungryforgod.php 